\title{
Loneliness and Their Relationship to Explicit and Implicit Self-Esteem
}

\author{
Yuanyan $\mathrm{Hu}^{1,2}$, Yule $\mathrm{Jin}^{1,3}$, Chunmei $\mathrm{Hu}^{1}$, Huamin $\mathrm{He}^{1 *}$ \\ ${ }^{1}$ School of Education, Chongqing University of Arts and Sciences, Chongqing, China \\ ${ }^{2}$ Laboratory of Cognition and Mental Health, Chongqing University of Arts and Sciences, Chongqing, China \\ ${ }^{3}$ School of Education, Zhangzhou Normal University, Zhangzhou, China \\ Email: "hhm6666@163.com, huyypsy@126.com
}

Received February $27^{\text {th }}, 2013$; revised March $29^{\text {th }}, 2013$; accepted April 26 $6^{\text {th }}, 2013$

\begin{abstract}
Copyright (C) 2013 Yuanyan Hu et al. This is an open access article distributed under the Creative Commons Attribution License, which permits unrestricted use, distribution, and reproduction in any medium, provided the original work is properly cited.
\end{abstract}

\begin{abstract}
The purpose of this study was to investigate the relationship between self-esteem and loneliness, especially whether the discrepancies between explicit and implicit self-esteem was associated with loneliness. In the present study, UCLA Loneliness Scale (UCLA), Rosenberg's Self-Esteem Scale (RSES) and Implicit Association Test were used to collect data, 113 undergraduates participated in it. Findings showed that individuals higher in explicit (but not implicit) self-esteem had lower loneliness. Furthermore, we found that the undergraduates' feelings of loneliness were significantly related to the direction of the discrepancy between explicit and implicit self-esteem. These results not only enriched the research about the loneliness, but also the discrepant self-esteem.
\end{abstract}

Keywords: Loneliness; Self-Esteem; Explicit; Implicit; Discrepant

\section{Introduction}

Loneliness is a prevalent social phenomenon, probably few people can say that I can avoid being loneliness (Cacioppo \& Patrick, 2008). Especially, adolescents are considered as one of the highest risk groups experiencing loneliness. As adolescence is developing rapidly, they are apart from their parents, going to be individual completely, and having increasing need for intimacy (Gürsesa, Merhametlia, Elif, \& Güne, 2011). For these reasons, adolescence is sensitive about loneliness, affected by loneliness. Many investigators have gained insight into it in the past decades (Hawkley \& Cacioppo, 2010; Russell, Cutrona, McRae, \& Gomez, 2012). By the concept, loneliness, as a universal unpleasant experience, occurs when human beings feel the absence of adequate and positive social relationships. That is, loneliness arises with the discrepancy between individual's desire and despair. Additionally, the dissatisfaction of social relationship results in loneliness. In this definition there are three aspects should not be ignored: first, loneliness results from deficiencies in the person's social relations; second, loneliness is a subjective phenomenon (Although someone stay with a group of friends and still feel alone; Even if a person in the room, and with no loneliness at all); third, loneliness is unpleasant and distressing (Perlman \& Peplau, 1981).

Cognitive psychologists (Segal, 1988) have suggested that loneliness is a form of internalizing problem which was based upon ones' early experience of life, mean while, negative schemas are including in memory. Self-schema is a cognitive construct, it is based on past experience to guide the self-information, especially the self-information processing in the

${ }^{*}$ Corresponding author. social interaction (Taylor \& Crocker, 1981). Furthermore, self-schema is the foundation of self-awareness and self-evaluation (Markus, 1977), so negative self-schema often leads to negative self-evaluations, and self-information was processed in a negative way. Explicit self-esteem as a kind of self-schema can be defined as an individual's conscious feeling of self-worth and acceptance (Rosenberg, 1965). A bulk of studies on adolescents has demonstrated a negative relationship between loneliness and explicit self-esteem (Creemers, Scholte, Engels, Prinstein, \& Wiers, 2012; Kamatha \& Kanekara, 1993; Hudson \& Campbell, 2000). As Greenwald and Banaji (1995) pointed out, self-esteem not only contains explicit aspects, but also implicit ones. Thus, it is necessary to use suitable measurements to capture the two parts of self-esteem (i.e., direct measurements for explicit self-esteem and indirect one for implicit self-esteem).

The previous studies suggested that implicit self-esteem could also relate to internalizing psychological problems (Creemers et al., 2012). Implicit self-esteem is defined as individuals' over learned automatic and unconscious self-evaluation (Greenwald \& Banaji, 1995). Although explicit self-esteem and implicit self-esteem are largely independent of each other, as conceptualized by dual-process models of information processing, the former refers to cognitive mode, the latter refers to experiential mode (Wilson, Lindsey, \& Schooler, 2000). As explicit and implicit attitudes are involved in different process and may lead to inconsistencies of explicit and implicit self-esteem, so it is possible for discrepant self-esteem to form: defensive (high explicit, low implicit) and damaged (high implicit, low explicit) self-esteem (Gawronski \& Bodenhausen, 2006). It was suggested that, compared to congruent self-esteem, the discrepant self-esteem associated with painful internal tension and unpleasant experience (Cockerham, Stopa, \& Gregg, 2009), and 
was related to more days of impaired mental health (Schröderabe, Rudolph, \& Schütz, 2007) because of difficulties with self-integration and conflicting thoughts (Stieger, Formann, \& Burger, 2011).

To sum up, the aim of this study was to investigate the relationship between self-esteem and loneliness, especially whether implicit self-esteem affects on loneliness the same as explicit self-esteem. Moreover, whether the discrepancy between explicit and implicit self-esteem was associated with loneliness?

\section{Method}

\section{Participants}

As volunteers, 113 (43 female) students from Chongqing University of Arts and Sciences participated in the study. Their ages ranged from 18 to $22(M=20.01)$. After the end of the experiment, we thanked the participants and paid them a little money.

\section{Procedure}

Each participant took part in the experiment individually. Unique subject number instead of their name was affiliated with the test results when the data was reported. At the beginning, they were noticed there were two parts in this study. In the first part, they were measured by the Rosenberg Self-Esteem Scale (RSES) and UCLA Loneliness Scale (UCLA). In the second part, they completed Implicit Association Test (IAT), in order to examining implicit self-esteem.

\section{Measures}

- The Rosenberg Self-esteem Scale (RSES; Chinese Version: Wang, Wang, \& Ma, 1999) was used to measure the undergraduates' global self-worth and self-acceptance. The RSES is a 10-item measure of explicit self-esteem, the higher scores reflects the higher explicit self-esteem $(\alpha=0.79)$.

- Implicit Association Test (IAT; Greenwald, Nosek, \& Banaji, 2003) was used to measure the implicit self-esteem.

- UCLA Loneliness Scale (UCLA, $3^{\text {rd }}$ edition; Chinese Version: Wang et al., 1999) was used to measure loneliness that comes about through a discrepancy between desired and achieved levels of social contact (Perlman \& Peplau, 1981). It is a 20 -item measure of loneliness, the lower scores reflects the lower loneliness $(\alpha=0.85)$.

\section{Data Analysis}

Hierarchical multiple regression were conducted to examine whether implicit self-esteem, explicit-esteem and their discrepancy was relate to loneliness.

Firstly, in order to investigate whether explicit and implicit self-esteem were relate to loneliness, we entered explicit and implicit self-esteem in Step 1 and their interaction in Step 2. All the variables were centered before entering into the regression equation.

Subsequently, we tested whether the discrepancy between explicit and implicit self-esteem was associated with loneliness. To calculate the discrepancy, explicit and implicit self-esteem were standardized, and then computed the absolute value of their difference (Creemers et al., 2012). High score of this va- riable reflected the discrepancy between explicit and implicit self-esteem. If the score was negative, it indicated the low explicit self-esteem and high implicit self-esteem; if the score was positive, it indicated the high explicit self-esteem and low implicit self-esteem. There were 61 participants had higher explicit than implicit self-esteem, and 52 participants had higher implicit than explicit self-esteem. Then, hierarchical regression analyses were performed, the size of discrepancy (was centered before being entered into the equation) between explicit and implicit self-esteem, and the direction of the discrepancy (implicit $<$ explicit or implicit $>$ explicit, dummy variable) were entered in step 1 and their interaction in Step 2.

\section{Results}

Descriptive statistics (i.e., Mean and SD) and correlations between the IAT, explicit measures, and the UCLA loneliness were computed (Table 1). Replicating many past results, the IAT and explicit measures were uncorrelated. In addition, the explicit self-esteem measures employed in this study were negatively correlated with loneliness, while implicit self-esteem measures were not correlated with loneliness.

\section{Associations of Explicit and Implicit Self-Esteem with Loneliness}

Multiple hierarchical regressions were conducted to investigate different possibility of interrelations between implicit and explicit self-esteem. All predictors were centred on their means respectively before calculating. With loneliness (see Table 2), a significant main effect of explicit self-esteem was found $(B=$ $-0.441, t=-4.56, p<0.001)$, but no significant main effect of implicit self-esteem $(B=-15.428, t=-1.486, p=0.140)$ or interaction between explicit and implicit self-esteem $(B=0.450, t$ $=1.255, p=0.212$ ).

\section{Associations of Explicit-Implicit Discrepancy with Loneliness}

Subsequently, a series of hierarchical multiple regressions were conducted to examine whether the size of the discrepancy,

Table 1.

Correlations among the measures and descriptive statistics.

\begin{tabular}{ccccc}
\hline & 2 & 3 & Mean & SD \\
\hline 1. Explicit SE & 0.03 & $-0.44^{* *}$ & 28.96 & 3.94 \\
2. Implicit SE & & -0.15 & 0.53 & 0.38 \\
3. UCLA loneliness & & & 42.50 & 6.76 \\
\hline ** & & &
\end{tabular}

Note: ${ }^{* *} p<0.01$.

Table 2.

Regression analysis with explicit self-esteem, implicit self-esteem, and their interaction as predictors of loneliness.

\begin{tabular}{cccc}
\hline & & \multicolumn{2}{c}{ UCLA loneliness } \\
\cline { 3 - 4 } & & $B$ & $t$ \\
\hline \multirow{2}{*}{ Step 1 } & Explicit SE & -0.943 & $-4.558^{* * *}$ \\
& Implicit SE & -15.428 & -1.486 \\
Step 2 & Explicit $\times$ implicit SE & 0.450 & 1.255 \\
\hline Note: ${ }^{* * *} p<0.01$. & &
\end{tabular}


the direction of the discrepancy and their interaction associates with loneliness.

Results in Table 3 showed that the association between the size of the discrepancy and loneliness was not significance $(B=$ $0.398, t=0.352, p=0.726)$. The direction of the discrepancy was negatively related to loneliness $(B=2.621, t=2.052, p<$ $0.05)$. The interaction between the size of the discrepancy and the direction of the discrepancy related to loneliness was not significance $(B=-1.367, t=-0.125, p=0.377)$.

\section{Discussion}

The present study examined the association between explicit self-esteem, implicit self-esteem and loneliness. We established that explicit self-esteem is negatively related to loneliness, while implicit self-esteem was not related to loneliness. These findings consist with previous studies (Creemers et al., 2012; Kamatha \& Kanekara, 1993; Hudson \& Campbell, 2000; Man $\&$ Hamid, 1998). There are several reasons explaining the results. On the one hand, researchers believed that the explicit self-esteem was a significant predictor for a variety of outcomes. For example, explicit self-esteem related to subject well-being and psychological health positively (Baumeister, Campbell, Krueger, \& Vohs, 2003), but related to suicidal ideation and depression negatively (Creemers et al., 2012). It was also consistent with the view of cognitive psychology. Researchers proposed that individuals with low explicit self-esteem, he/she will show more internalizing symptoms, which may be due to dysfunctional self-schemas existing in memory (Clark, Beck, \& Alford, 1999). For this reason, it is necessary to examine the relationship between implicit self-esteem and loneliness. On the other hand, the results showed that the implicit self-esteem is not linked to mental health. There are a number of reasons responsible for the results. First, implicit self-esteem restores historically positive self-views (Jordan, Spencer, Zanna, Etsuko, Correll, \& Joshua, 2003) or buffers against the negative effects of low explicit self-esteem (Bosson, Brown, Zeigler-Hill, \& Swann, 2003), so it only predicts a part of positive emotion significantly, and does not predict negative emotion. Second, implicit self-esteem is relatively independent of explicit selfesteem, which was based on positive self-schemata and automated self-representation. According to the Dual-Attitude Model (Wilson, Lindsey, \& Schooler, 2000), it was assumed that explicit self-esteem changes relatively easily, whereas implicit self-esteem, like old habits, changes more slowly. Explicit selfesteem is more susceptible to the impact of unexpected life events, and loneliness largely by the specific period of changed environment. Thus, loneliness can be pre unexpected life events,

Table 3.

Regression analysis with the size of discrepancies between explicit and implicit self-esteem, the direction of the discrepancy, and their interaction as predictors of loneliness.

\begin{tabular}{cccc}
\hline & & \multicolumn{2}{c}{ UCLA loneliness } \\
\cline { 3 - 4 } & & $B$ & $t$ \\
\hline Step & Size of the discrepancy & 0.398 & 0.352 \\
1 & Direction of the discrepancy & 2.621 & $2.052^{*}$ \\
Step & Size of the discrepancy $\times$ direction of & 1.367 & 0.125 \\
\hline $\begin{array}{c}\text { the discrepancy } \\
\text { Note: }{ }^{*} p<0.5 .\end{array}$ & & \\
\end{tabular}

and loneliness largely by the specific period of changed environment. Thus, loneliness can be predicted by explicit (not implicit) self-esteem. Consequently, we still lack sufficient knowledge of implicit self-esteem. Moreover, the complexity of the construct of implicit self-esteem may be beyond our imagination, the existing research methods may be difficult to uncover the veil of mystery, so we need more in-depth research about implicit self-esteem so as to really understanding its construct and the effect on other psychological factors. Those may be the reasons why explicit self-esteem does indicate loneliness, nevertheless, implicit self-esteem does not predict loneliness.

Although implicit self-esteem does not predict loneliness, we explored further for the associations of the discrepancy between explicit and implicit self-esteem with loneliness. Consistent with previous study (Creemers et al., 2012), results showed that the direction of the discrepancy was positively relate to loneliness. This means that participants with damaged self-esteem had higher scores on loneliness than others. There are several explanations for why the damaged self-esteem related to loneliness positively. First, this may be because a high interpersonal goal for her/himself were deeply set in her/his heart, whereas the reality did not reach the goal, then the unpleasant experience occurred. Second, as researchers (Olson, Fazio, \& Hermann, 2007) demonstrated that individuals with low implicit self-esteem and high explicit self-esteem were more likely to rate themselves boastfulness, and over-present themselves, so they were more likely to exhibit a lower sense of loneliness. Finally, damaged self-esteem is easily hurt and influenced by certain affairs. In addition, it results in unsatisfied interpersonal relationship. To sum up, the discrepant self-esteem, especially the damaged (i.e. combined with high explicit and low implicit) self-esteem make individual feel loneliness more sensitively.

There are a number of limitations in the present study. First, implicit self-esteem was measured by only one method of measurement, the Implicit Association Test. Other measures of implicit self-esteem should be conducted in the future research. Second, when we performed regression analysis, the demographic variables were not been controlled, perhaps gender and other factors will interfere with the results. Despite the inadequacies, our study proves that the implicit self-esteem is a relatively independent construct indeed, as well as the role of the discrepant self-esteem in internalizing problems should be pay more attention.

\section{Acknowledgements}

This study was supported by the Planning Project of Social Science of Chongqing, China (Grant 2009JY15). We thank Guiping Huang, Zhenliang Shi for assistance in data collection.

\section{REFERENCES}

Ahmet Gürsesa, Z., Rukiye, M., Elif, A., Kübra, G., \& Metin, A. (2011). Psychology of loneliness of high school students. Procedia Social and Behavioral Sciences, 15, 2578-2581. doi:10.1016/j.sbspro.2011.04.149

Anthony, G., Greenwald, Brian, A. N., \& Mahzarin, R. B. (2003). Understanding and using the implicit association test: An improved scoring algorithm. Journal of Personality and Social Psychology, 85, 197-216. doi:10.1037/0022-3514.85.2.197

Roy, F., Baumeister, J. D., Campbell, J. I., Krueger, \& Kathleen, D. V. (2003). Does high self-esteem cause better performance, interperso- 
nal success, happiness, or healthier lifestyles? Psychological Science in the Public Interest, 4, 1-44. doi:10.1111/1529-1006.01431

Bosson, J. K., Brown, R. P., Zeigler-Hill, V., \& Swann Jr., W. B., (2003). Self-enhancement tendencies among people with high explicit self-esteem: The moderating role of implicit self-esteem. Self and Identity, 2, 169-187. doi:10.1080/15298860309029

John, T. C., \& William, P. (2008). Loneliness: Human nature and the need for social connection. New York: W.W. Norton.

Clark, D. A., Beck, A. T., \& Alford, B. A. (1999). Scientific foundations of cognitive theory and therapy of depression. New York: Wiley.

Cockerham, E., Stopa, L., Bell, L., \& Gregg, A. (2009). Implicit selfesteem in bulimianervosa. Journal of Behavior Therapy and Experimental Psychiatry, 40, 265-273. doi:10.1016/j.jbtep.2008.12.003

Daan, H. M. Creemers, R. H. J., Scholte, R. C. M. E., Engels, M., Prinstein, J., \& Reinout, W. (2012). Implicit and explicit self-esteem as concurrent predictors of suicidal ideation, depressive symptoms, and loneliness. Journal of Behavior Therapy and Experimental Psychiatry, 43, 638-646. doi:10.1016/j.jbtep.2011.09.006

Daniel, P. \& Letitia, A. P. (1981). Toward a social psychology of loneliness. London: Academic Press.

Daniel, W. R., Carolyn, E. C., Cynthia, M., \& Mary, G. (2012). Is loneliness the same as being alone? The Journal of Psychology: Interdisciplinary and Applied, 146, 7-22. doi:10.1080/00223980.2011.589414

Gawronski, B., \& Bodenhausen, G. V. (2006). Associative and propositional processes in evaluation: An integrative review of implicit and explicit attitude change. Psychological Bulletin, 132, 692-731. doi:10.1037/0033-2909.132.5.692

Greenwald, A. G., \& Banaji, M. R. (1995). Implicit social cognition: Attitudes, self-esteem, and stereotypes. Psychological Review, 102, 4-27. doi:10.1037/0033-295X.102.1.4

Hudson, D. B., Elek, S. M., \& Campbell-Grossman, C. (2000). Depression, self-esteem, loneliness, and social support among adolescent mothers participating in the new parents project. Adolescence, 139, 445-453.

Jordan, C. H., Spencer, S. J., Zanna, M. P., Hoshino-Browne, E., \& Correll, J. (2003). Secure and defensive high self-esteem. Journal of Personality and Social Psychology, 85, 969-978. doi: 10.1037/0022-3514.85.5.969

Ka-on, M., \& Hamid, P. N. (1998). The relationship between attachment prototypes, self-esteem, loneliness and causal attributions in Chinese trainee teachers. Journal of Personality and Individual Differences, 3, 357-371. doi:10.1016/S0191-8869(97)00185-2

Louise, C. H., \& John, T. C. (2010). Loneliness matters: A theoretical and empirical review of consequences and mechanisms. Annals of Behavioral Medicine, 40, 218-227. doi:10.1007/s12160-010-9210-8

Malavika, K., \& Suresh, K. (1993). Loneliness, shyness, self-esteem and extraversion. Journal of Social Psychology, 6, 855-857. doi: 10.1080/00224545.1993.9713949

Markus, H. (1977). Self-schemata and processing information about the self. Journal of Personality and Social Psychology, 35, 63-78.

Michela, S., Almut, R., \& Astrid, S. (2007). High implicit self-esteem is not necessarily advantageous: Discrepancies between explicit and implicit self-Esteem and their relationship with anger expression and psychological health. European Journal of Personality, 21, 319-339. doi: $10.1002 /$ per. 626

Olson, M. A., Fazio, R. H., \& Hermann, A. D. (2007). Reporting tendencies underlie discrepancies between implicit and explicit measures of self-esteem. Psychological Science, 4, 287-291. doi:10.1111/j.1467-9280.2007.01890.x

Rosenberg, M. (1965). Society and the adolescent self-image. Princeton, NJ: Princeton University Press.

Stefan, S., Anton, K. F., \& Christoph, B. (2011). Humor styles and their relationship to explicit and implicit self-esteem. Personality and Individual Differences, 50, 747-750. doi:10.1016/j.paid.2010.11.025

Taylor, S. E., \& Crocker, J. (1981). Social cognition bases of social information processing. In E. T. Higines, C. P. Herman, \& M. P. Zanna (Eds.), The ontario symposium (pp. 89-134). Hillsdale, NJ: Erlbaum.

Timothy, D. W., Samuel, L., \& Tonya. Y. S. (2000). A model of dual attitudes. Psychological Review, 107, 101-126. doi:10.1037/0033-295X.107.1.101

Wang, X. D., \& Wang, X. L. (1999). Rating scales for mental health. Beijing: Chinese Mental Health Journal Press.

Zindel, V. S. (1988). Appraisal of the self-schema construct in cognitive models of depression. Psychological Bulletin, 2, 147-162. doi:10.1037/0033-2909.103.2.147 